ARTICLE

DOI: $10.1038 / s 41467-017-02606-w$

\title{
Gs- versus Golf-dependent functional selectivity mediated by the dopamine $D_{1}$ receptor
}

Hideaki Yano ${ }^{1}$, Ning-Sheng Cai ${ }^{1}$, Min Xu ${ }^{1}$, Ravi Kumar Verma ${ }^{1}$, William Rea', Alexander F. Hoffman ${ }^{1}$, Lei Shi ${ }^{1}$ Jonathan A. Javitch ${ }^{2,3}$, Antonello Bonci ${ }^{1} \&$ Sergi Ferré ${ }^{1}$

The two highly homologous subtypes of stimulatory G proteins Gas (Gs) and Goolf (Golf) display contrasting expression patterns in the brain. Golf is predominant in the striatum, while Gs is predominant in the cortex. Yet, little is known about their functional distinctions. The dopamine $D_{1}$ receptor (D1R) couples to Gs/olf and is highly expressed in cortical and striatal areas, making it an important therapeutic target for neuropsychiatric disorders. Using novel drug screening methods that allow analysis of specific G-protein subtype coupling, we found that, relative to dopamine, dihydrexidine and $\mathrm{N}$-propyl-apomorphine behave as full D1R agonists when coupled to Gs, but as partial D1R agonists when coupled to Golf. The Gs/Golfdependent biased agonism by dihydrexidine was consistently observed at the levels of cellular signaling, neuronal function, and behavior. Our findings of Gs/Golf-dependent functional selectivity in D1R ligands open a new avenue for the treatment of cortex-specific or striatumspecific neuropsychiatric dysfunction.

\footnotetext{
${ }^{1}$ National Institute on Drug Abuse, National Institutes of Health, Baltimore, MD 21224, USA. ${ }^{2}$ Department of Psychiatry, College of Physicians \& Surgeons, Columbia University, New York, NY 10032, USA. ${ }^{3}$ Division of Molecular Therapeutics, New York State Psychiatric Institute, New York, NY 10032 , USA. Correspondence and requests for materials should be addressed to H.Y. (email: hideaki.yano@nih.gov)
} 
F unctional selectivity is defined as the ability of a ligand to demonstrate a biased profile of potency or efficacy on different signaling pathways. This is distinguished from prototypical uniform activation by general agonism ${ }^{1,2}$ produced by endogenous ligands. In recent years, many ligands with functionally selective properties for G-protein-coupled receptors (GPCRs) have emerged based on the concept that ligands can stabilize specific receptor conformations to which different signaling proteins, such as $\mathrm{G}$ proteins and $\beta$-arrestins, couple ${ }^{1}$. In addition, accessory proteins to the receptor ${ }^{3}$ as well as effector proteins ${ }^{4}$ may exert bias in signaling events exhibiting many potential sites for functional selectivity. Thus the concept of functional selectivity has provided a new avenue for the development of drugs with safer therapeutic index, when therapeutic and unwanted side effects are dependent on different signaling pathways ${ }^{5}$.

Several examples of functional selectivity have been reported for dopamine receptor ligands. Dopamine receptors are classified into Gs/Golf-coupled $\mathrm{D}_{1}$-like receptors (D1R and D5R) and Gi/ocoupled $\mathrm{D}_{2}$-like receptors (D2R, D3R and D4R). With respect to $\mathrm{D}_{2}$-like receptors, both G-protein-biased ${ }^{6,7}$ and $\beta$-arrestinbiased $^{8,9}$ agonists have been characterized. With respect to $D_{1}$ like receptors, biased agonism at G-protein versus $\beta$-arrestin signaling has also been reported ${ }^{10-12}$. We recently found differences in dopamine potency in promoting the coupling of different

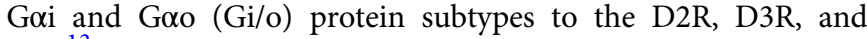
$D 4 R^{13}$. These results suggest the possibility of selectively targeting $\mathrm{D}_{2}$-like receptor in different brain areas relying on the predominant local expression of certain Gi/o proteins. However, there is no compelling evidence for a differential distribution of Gi/o proteins in the brain. This is in contrast with the clearly distinct distribution of the two subtypes of stimulatory G proteins, Gs and Golf. Golf is by far the most expressed and functions as a signaling G-protein for D1R in the striatum ${ }^{14}$, while Gs is predominantly expressed in cortical and other areas ${ }^{15,16}$.

In the present study, using a series of novel pharmacological assays, we addressed the possibility of Gs/olf protein subtypedependent biased agonism of D1R ligands. Dihydrexidine (DHX) and N-propyl-apomorphine (NPA) behaved as full D1R agonists when coupled to Gs and as partial D1R agonists when coupled to
Golf. The significant efficacy bias for Gs-mediated versus Golfmediated signaling of DHX was further demonstrated with cellular signaling, electrophysiological and psychomotor activation experiments, which enhances our understanding of Golfsignaling in striatal function and psychomotor activity. Moreover, our results highlight the potential use of such functionally selective agonists for treating the "negative" cognitive symptoms of schizophrenia ${ }^{17}$.

\section{Results}

Gs- and Golf-biased engagement and activation by D1R ligands. Using the receptor-Go subunit engagement BRET configuration, the potencies and efficacies of different classes of D1R agonists were compared to dopamine for Gs and Golf coupling (Fig. 1 and Table 1). While the majority of the compounds behaved similarly for the engagement of Gs and Golf, two compounds, dihydrexidine (DHX) and N-propyl apomorphine (NPA), behaved quite differently (Fig. 1c, d; green and yellow curves, respectively). Notably, whereas these compounds behaved as full agonists (relative to DA) for Gs coupling ( $E_{\max }$; DHX, $121.3 \%$; NPA, $111.9 \%)$, they displayed only partial agonism for Golf coupling ( $E_{\max }$; DHX, 39.0\%; NPA, 67.9\%; Fig. 1 and Table 1). To further validate the partial efficacy of DHX for Golf engagement, DHX was tested for its ability to counteract the agonist effect of dopamine (1 $\mu \mathrm{M}$; Supplementary Fig. 1B). Although much less potent than the commonly used D1R antagonist SCH23390, the $I_{\max }$ value of DHX was in agreement with its $E_{\max }$ value (Supplementary Fig. 1B). The relative potency and efficacy of the different agonists were further tested with the G $\alpha-\gamma$ activation BRET configuration (Supplementary Table 1). Similar to results obtained with the engagement assay, DHX and NPA exhibited significantly lower $E_{\max }$ values relative to DA for Golf activation (46.8 and 52.6\%; Supplementary Table 1) while retaining $E_{\max }$ values comparable to DA for Gs activation.

Although $\beta$-arrestin is essential for GPCR internalization and desensitization, it can also transduce MAPK activation for various receptors ${ }^{18}$, including $\mathrm{D} 1 \mathrm{R}^{19}$. Using the same luciferase-fused D1R construct used for the G $\alpha$ engagement BRET assays, we measured agonist-induced recruitment of Venus-fused $\beta$-arrestin2 to the D1R (Supplementary Table 1). GPCR kinase 2 (GRK2) a

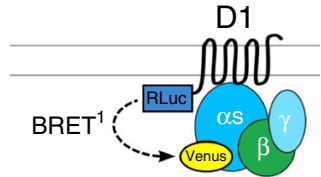

C

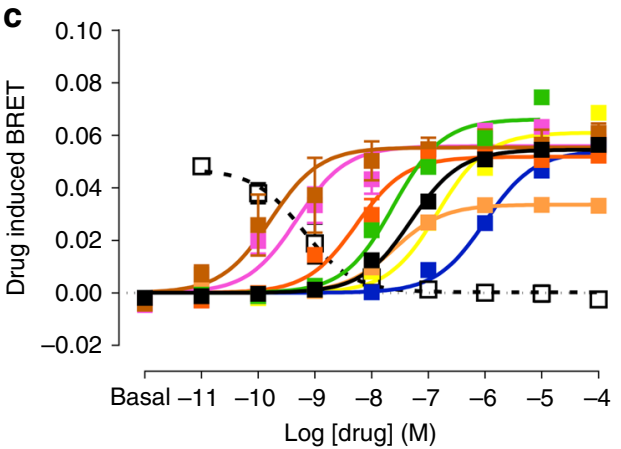

b

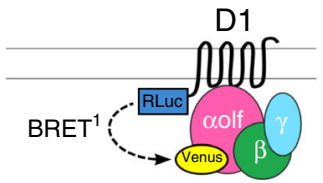

d

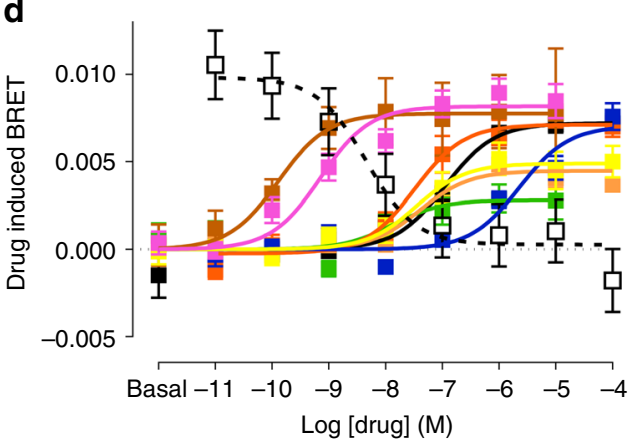

Fig. 1 a Scheme for the engagement BRET between D1R-Rluc and Gs-Venus. b Scheme for the engagement BRET between D1R-Rluc and Golf-Venus. c Dose-response curves of drug-induced BRET between D1R-Rluc and Gs-Venus (black dopamine, blue norepinephrine, light orange SKF38393, dark orange SKF81297, brown SKF82958, yellow NPA, green DHX, magenta A77636, black open SCH23390 + 10 ${ }^{-6}$ SKF81297). d Dose-response curves of BRET between D1R-Rluc and Golf-Venus (same color scheme). The error bars represent S.E.M 
Table 1 Pharmacological comparison of Gs and Golf engagement in D1R

\begin{tabular}{|c|c|c|c|c|}
\hline & $\mathrm{EC}_{50}(\mathrm{nM})$ & $E_{\max }(\%)$ & $\mathrm{EC}_{50}(\mathrm{nM})$ & $E_{\max }(\%)$ \\
\hline$\overline{D A}$ & $49.0 \pm 4.3$ & $100.0 \pm 1.3$ & $111.9 \pm 25.4$ & $100.0 \pm 3.9$ \\
\hline SKF38393 & $25.1 \pm 4.0$ & $61.6 \pm 1.3^{c}$ & $40.6 \pm 14.6$ & $62.1 \pm 4.2^{c}$ \\
\hline SKF81297 & $5.4 \pm 1.2^{c}$ & $95.0 \pm 2.7$ & $32.6 \pm 12.7$ & $98.8 \pm 7.4$ \\
\hline SKF82958 & $0.2 \pm 0.1^{c}$ & $101.5 \pm 5.2$ & $0.1 \pm 0.1^{c}$ & $107.6 \pm 11.0$ \\
\hline A77636 & $0.5 \pm 0.1^{c}$ & $102.5 \pm 3.8$ & $0.7 \pm 0.2^{c}$ & $113.4 \pm 5.6$ \\
\hline \multicolumn{5}{|c|}{ 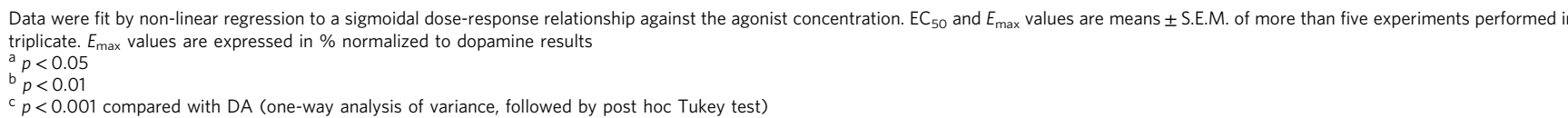 } \\
\hline
\end{tabular}

was co-transfected to enhance $\beta$-arrestin-2 recruitment. SKF81297 and SKF38393 showed reduced and minimal $\beta$-arrestin-2 recruitment, respectively, confirming their recently reported biased G-protein- versus $\beta$-arrestin-dependent signaling $^{12}$, while A77636 and SKF82958 maintained their high potencies and efficacies in the $\beta$-arrestin-2 recruitment assay. DHX and NPA behaved similarly to Gs engagement in terms of efficacy and potency and DHX also showed a significantly higher $E_{\max }$ value than DA (142.4\%; Supplementary Table 1). Altogether, these results clearly indicate that DHX and NPA possess biased agonism toward Gs versus Golf but not toward Gs protein versus $\beta$-arrestin selectivity.

G $\alpha$-D1R interface contribution to bias between Gs and Golf. We then inspected the sequence differences between Gs and Golf to identify a potential structural element that is responsible for the observed biased agonism. Most of the motifs that interact with D1R are nearly identical between Gs and Golf. However, five residues are divergent at the end of $\alpha \mathrm{N}$ helix of G-protein (residues 33-38 in Gs) apposing to the intracellular loop 2 (IL2) of D1R (Fig. 2). The impact of this divergence on the proteinprotein interaction was then investigated both in vitro and in silico. To understand the functional impact of this divergence in the D1R-G-protein coupling, a Golf/s chimeric construct was made whereby an ERLAYK to DKQVYR mutation was introduced to the Golf-Venus construct (Fig. 2a). The effect of DHX in the $\mathrm{D} 1 \mathrm{R}-\mathrm{G} \alpha$ engagement was then tested with this construct. DHX-induced BRET changes were normalized to the $E_{\max }$ values obtained by DA with the corresponding $\mathrm{G} \alpha$-Venus constructs (Fig. 2b). Similar to the results described above, Gs and Golf coupling were $123.3 \%$ and $46.8 \% E_{\max }$ relative to DA, confirming the biased selectivity of this ligand. In contrast, DHX coupling to the Golf/s chimera was significantly increased $\left(E_{\max }=94.0 \%\right.$ relative to DA). A partial but significant increase in $E_{\max }$ was also observed with NPA (Supplementary Fig. 1D). Thus, our results suggest that the G $\alpha / \alpha \mathrm{N}-\mathrm{D} 1 \mathrm{R} / \mathrm{IL} 2$ interface is responsible for the biased agonism of DHX on D1R-Gs vs D1R-Golf. As expected, a full agonist effect was observed in Golf/s chimera coupling nearly the same as Gs or Golf with SKF 81297 (Supplementary Fig. 1C). Further, to exclude the possibility of effects from other noncognate coupling, Gi1 and Gq engagement to the D1R was tested (Supplementary Fig. 1E, F). DA, SKF81297, or DHX did not cause any coupling of Gil or Gq while D2R-Gil coupling by DA and M1R-Gq coupling by carbachol were observed as positive controls (Supplementary Fig. 1E, F).
Next, the underlying molecular mechanism for the bias was explored with comparative homology modeling and molecular dynamics simulation. In the simulation of the D1R-Gs and D1RGolf homology models constructed from $\beta 2 \mathrm{AR}-\mathrm{Gs}$ complex (see Methods), we found that in the D1R-Gs complex, R38 of Gs forms a steady salt bridge interaction with E132 of D1R/IL2 (Fig. 2c), for which the simulation shows the interaction $(<4 \AA)$ holds for $89 \%$ of the time (Fig. 2e). In comparison, the D1R-Golf complex has a weaker salt bridge interaction between K40 of Golf and E132 of D1R/IL2 (Fig. 2d) with an intermittent interaction ( $<4 \AA$ ) of $54 \%$ within the simulated time (Fig. $2 \mathrm{~d}$ ). This reduced stability in salt bridge interaction between Golf/ $\alpha \mathrm{N}$ and D1R/IL2 is consistent with the lower signal observed in D1R-Golf BRET assay.

Gs-biased agonism of DHX at the cellular signaling level. To confirm the partial agonism of Golf-dependent signaling, DHX was tested in a novel G $\alpha$-AC5 coupling assay (Fig. 3 and Supplementary Table 2) in which D1R agonist-induced relative movement (BRET changes) between AC5 and Gs or Golf can be monitored. Assay optimization was first performed by testing various Gs and Golf biosensor constructs with different insertion positions (Supplementary Fig. 2). Ligand-induced BRET changes indicate relative conformational changes between Gs or Golf and AC5, reflecting AC5 activation level. D1R ligands were analyzed for the interactions between Gs and Golf and AC5 (Fig. 3). Again, DHX behaved as a more efficacious agonist than DA with Gs $\left(E_{\max } 119.0 \%\right)$, and as a partial agonist with Golf $\left(E_{\max } 37.6 \%\right.$; Suppl. Table 2 and Fig. 3). To confirm the results and validate this novel assay, we analyzed adenylate cyclase enzymatic activity, cAMP accumulation, in a unique lymphoma cell line (S49 cyccells) lacking Gs (Supplementary Fig. 3) ${ }^{20}$. In this cell line Gs- or Golf-dependent cAMP activation can be separately analyzed by rescuing the expression of either $\mathrm{G} \alpha$ protein subunit. In D1R electroporated cells, a selective full agonist SKF81297 and a selective partial agonist SKF38393 were used as reference compounds to compare with DHX. As expected, when compared to SKF81297 and SKF38393, $E_{\max }$ value for DHX yielded a similar partial efficacy value as SKF38393 with Golf co-transfection (45.1 and $50.3 \%$, respectively), while maintaining partial and near full efficacy values with Gs co-transfection (67.4 and $87.6 \%$, respectively). Forskolin was added to confirm G-protein-independent activation of endogenous AC (Supplementary Fig. 3C, mosaic bar). Increased cAMP production was observed in Golf or Gs electroporated cells compared to the mock electroporated cells due to AC5 co-electroporation in Golf and Gs cells 


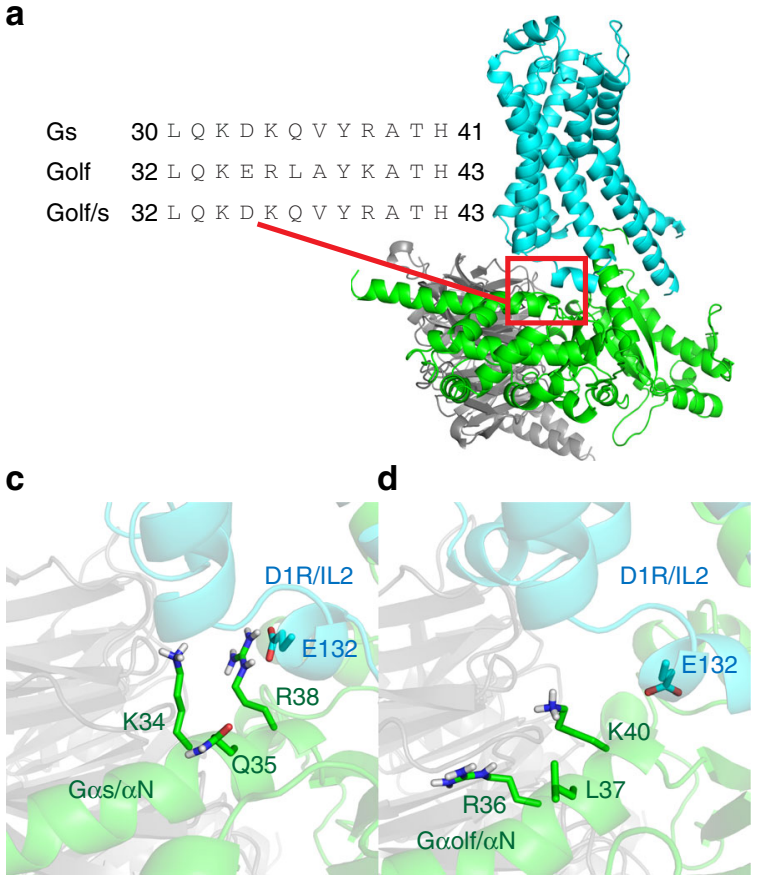

b

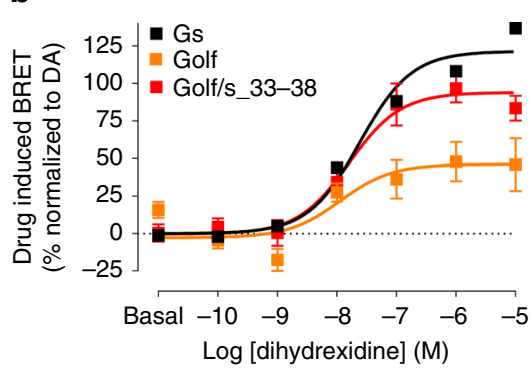

e

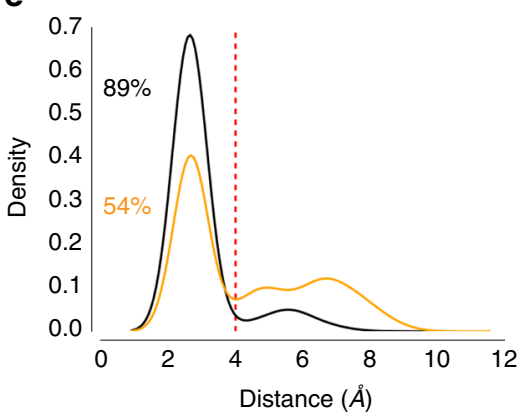

Fig. 2 a Homology modeling of Gs (green) coupling to D1R (cyan) based on $\beta 2 A R-G s$ crystal structure (PDB: 3SN6) with the amino acid alignment among Gs (top row), Golf (middle row), and Golf/s_33-38 chimera (bottom row). b Dose-response curves of DHX-induced BRET between D1R-Rluc and GsVenus, Golf-Venus, or Golf/s_33-38-Venus (black, orange, and red respectively). BRET values are normalized to $E_{\text {max }}$ values obtained by DA with corresponding $\mathrm{G} \alpha-V$ enus constructs. c, d Close-up views of the simulated interface between D1R and Gs (c) or D1R and Golf (d) at the intracellular loop 2 (IL2) of D1R and N-terminal $\alpha$-helix $(\alpha \mathrm{N})$ of $\mathrm{G} \alpha$ subunit. e Frequency density distribution plot of 50 ns simulation for D1R-Gs (black) and D1R-Golf (orange). Proportions of salt bridge occurance $(<4 \AA)$ in the simulation are shown in percentage. The error bars represent S.E.M.

(Supplementary Fig. 3C, solid and hatch bars vs. mosaic bar). In non-electroporated S49 cyc- cells, DHX or isoproterenol ( $\beta$-adrenergic receptor agonist) was added to demonstrate the lack of Gs/olf proteins, as there was no AC activation (Supplementary Fig. 3D, green mosaic and purple mosaic). The effect of isoproterenol was rescued by Golf or Gs electroporation (Supplementary Fig. 3D, purple solid and hatch bars). Finally, a BRET-based cAMP biosensor was used to verify the specificity and potency of SKF81297 and DHX in HEK293T cells (Supplementary Fig. 4A, B, E, F). Propranolol $(1 \mu \mathrm{M})$ was added to inhibit DA activation of $\beta$-adrenergic receptors (Supplementary Fig. 4E, F, black curves). The results demonstrate the lack of agonist activity for SKF81297 and DHX in non-D1R transfected cells (Supplementary Fig. 4A, E) and high potency and efficacy of SKF81297 and DHX in D1R-transfected cells (Supplementary Fig. 4B, F).

Gs-biased agonism of DHX in mouse brain tissue. Previous reports have shown contrasting patterns of Gs and Golf expression in the brain, with Golf enriched in the striatum but not in the cortex and vice versa for Gs ${ }^{15}$. Indeed, using single cell RT-PCR analysis in Drd1-tdTomato BAC reporter mice, we were able to confirm a preferential expression of Gs and Golf genes in the prelimbic region of medial prefrontal cortex (mPFC) and the shell of the nucleus accumbens (NAc), respectively (Supplementary Fig. 5A, B). Virtually the same results were obtained with tissue punches, confirming the same differential gene expression when also including non-D1R-expressing cells (Supplementary Fig. 5C, D). Electrophysiological studies in mouse slices from Gs-enriched mPFC and Golf-enriched NAc were performed to confirm the predicted low efficacy of DHX in the striatum. The D1R agonist SKF81297 was used for comparison and expected to behave with full efficacy in both preparations. Both compounds have been reported to bind to $\mathrm{D}_{2}$-like receptors albeit with lower affinity than $\mathrm{D} 1 \mathrm{R}^{21,22}$. Since $\mathrm{D}_{2}$-like receptors, especially $\mathrm{D} 3 \mathrm{R}$, co-localize with D1R in the brain ${ }^{23}$, the ability of both ligands to activate $\mathrm{D} 2 \mathrm{R}$ and D3R was also evaluated in BRET-based functional assays. DHX and SKF81297 were about one order of magnitude less potent and less efficacious at D2R and D3R-mediated Go activation than at D1R-mediated Gs activation (Supplementary Figs. $4 \mathrm{C}, \mathrm{D}, \mathrm{G}, \mathrm{H}, 6$ ). Nevertheless, the non-selective $\mathrm{D}_{2}$-like receptor antagonist eticlopride was co-applied with DHX or SKF81297 to completely isolate D1R agonist-mediated effects in the brain slice preparation.

Increased neuronal excitability and cell firing mediated by D1R activation has been reported in the striatum ${ }^{24-26}$ as well as in the cortex ${ }^{27-29}$. D1R and NMDA receptors (NMDAR) have been reported to form molecular and functional interactions ${ }^{30-32}$ and D1R activation has been shown to facilitate NMDAR function via Gs/olf-AC-PKA activation ${ }^{33}$. Differences in Gs- and Golfdependent effects of SKF81297 and DHX were therefore assessed by measuring NMDA-induced firing rates in D1R-expressing neurons using patch-clamp electrophysiology in slices from Drd1-tdTomato mice. First, firing rate was analyzed in D1Rexpressing layer $\mathrm{V}$ pyramidal neurons in the Gs-enriched $\mathrm{mPFC}$ (Fig. 4a). The minimal basal spontaneous firing rate $(0.010 \pm$ $0.006 \mathrm{~Hz})$ was dramatically increased by NMDA $(10 \mu \mathrm{M} ; 0.298 \pm$ $0.061 \mathrm{~Hz} ; 2830 \%$ of basal), and this was further enhanced by coapplication of SKF81297 $(10 \mu \mathrm{M} ; 0.902 \pm 0.229 \mathrm{~Hz} ; 8570 \%$ of basal; $p<0.01)$ or DHX $(10 \mu \mathrm{M} ; 0.689 \pm 0.244 \mathrm{~Hz} ; 6540 \%$ of basal; $p<0.05$ ). The enhancement of NMDA-induced firing by SKF81297 and DHX was blocked by the D1R antagonist $\mathrm{SCH} 23390$. Spontaneous firing, as well as NMDA-induced firing, was absent in NAc medium spiny neurons owing to their hyperpolarized resting membrane potentials. Therefore, in the Golf-enriched NAc, $200 \mathrm{pA}$ was injected to elicit cell firing (Fig. 4b). NMDA $(10 \mu \mathrm{M})$ robustly increased the elicited spike 
a
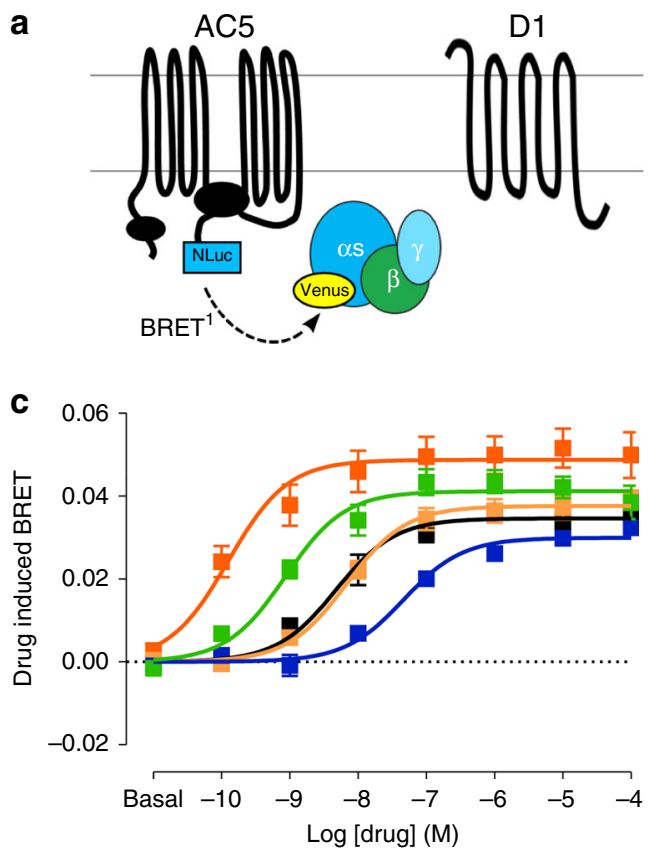

b
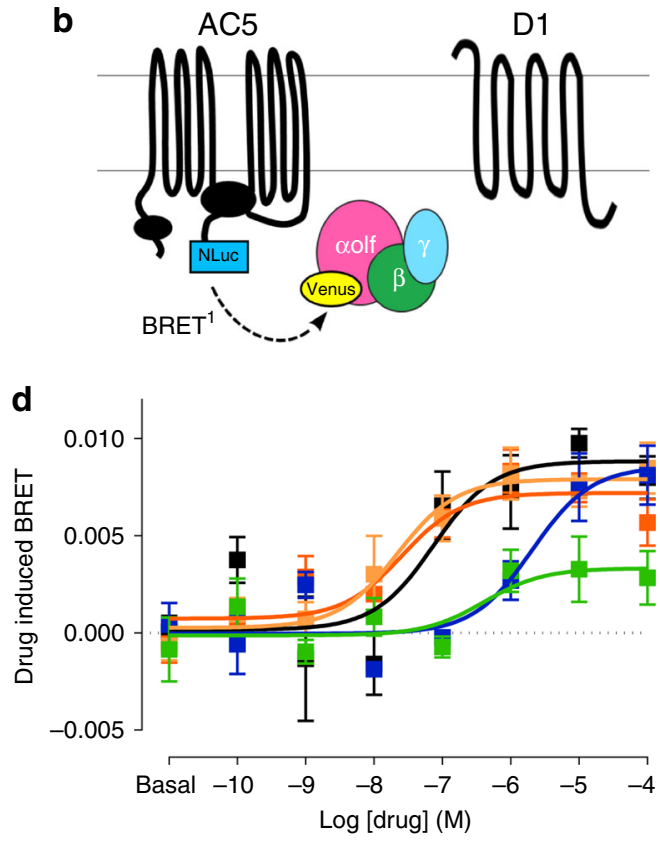

Fig. 3 a. Scheme for the drug-induced interaction BRET between AC5-Nluc and Gs-Venus. b Scheme for the drug-induced interaction BRET between AC5Nluc and Golf-Venus. c Dose-response curves of drug-induced BRET between AC5-Nluc and Gs-Venus (black DA, blue norepinephrine, light orange SKF38393, dark orange SKF81297, green DHX, black open SCH23390 + 10 ${ }^{-6}$ SKF81297). d Dose-response curves of drug-induced BRET between AC5Nluc and Golf-Venus (same color scheme). The error bars represent S.E.M.

frequency (198\% of control aCSF), and this was further enhanced by SKF81297 ( $291 \%$ of basal; $p<0.01$ vs. NMDA). The effect of SKF81297 was inhibited by SCH23390. However, in contrast to the results obtained in the $\mathrm{mPFC}$, DHX failed to further potentiate NMDA-induced increases in firing rate $(215 \%$ of basal; $p>0.05$ vs. NMDA). The D1R agonists by themselves, without NMDA application, did not enhance the firing rate in mPFC or NAc slices (Supplementary Fig. 7), indicating the need for concurrent NMDA-dependent cellular depolarization, although other ion channels may also be involved in the D1R agonist-mediated firing increase ${ }^{34}$. As previously reported ${ }^{35}$, SCH23390 partially inhibited the NMDA effect in both mPFC and NAc (Supplementary Fig. 7), indicating a possible direct interaction of SCH23390 with NMDAR as well as an effect from blocked basal DA tone. Together, these results suggest that the Gs-biased agonist DHX promotes unique effects on the activity of native neuronal cells that differentially express Gs and Golf.

Weak psychomotor activating properties of DHX. Finally the ability of DHX to produce psychomotor activity by activating striatal D1R was explored in the catecholamine depleted longterm (twenty hours) reserpinized mouse model (Fig. 5) ${ }^{36,37}$. This model allows the in vivo determination of separate striatal postsynaptic activity of selective D1R and D2R agonists without the confounding influence of endogenous dopamine. Thus, either a selective $\mathrm{D} 1 \mathrm{R}$ or a $\mathrm{D} 2 \mathrm{R}$ agonist produces significant locomotor activation of the akinetic animal ${ }^{36,37}$. Both DHX and SKF81297 dose-dependently induced significant locomotor activation (Fig. 5a, b; see Supplementary Fig. 8B, C for time course), which was blocked by the $\mathrm{D}_{1}$-like receptor antagonist $\mathrm{SCH} 23390(0.5$ $\mathrm{mg} / \mathrm{kg})$, but not by the $\mathrm{D}_{2}$-like antagonist eticlopride $(0.5 \mathrm{mg} / \mathrm{kg})$. The same dose of eticlopride, but not SCH23390, blocked quinpirole-induced locomotor activation (Supplementary Fig. 8A). These results demonstrated a selective involvement of D1R versus D2R in the locomotor activation and D1R-specific locomotor effects by DHX and SKF81297. Importantly, and consistent with its partial efficacy on the Golf-coupled striatal D1R, DHX showed a significantly lower locomotor-activating effect compared to the full agonist SKF81297 (Fig. 5c, d; 48.6\% at $5 \mathrm{mg} / \mathrm{kg}$ or $45.8 \%$ at $15 \mathrm{mg} / \mathrm{kg}$ ).

\section{Discussion}

The development of D1R pharmacology for over 30 years has verified its potential therapeutic value in various neuropsychiatric disorders, including Parkinson's disease, schizophrenia and substance use disorders. Intense research in GPCR pharmacology has yielded the concept of functional selectivity, giving rise to the possibility of selective targeting aside from receptor affinity, particularly the ability of ligands to preferentially activate either G-protein-mediated or $\beta$-arrestin-mediated signaling ${ }^{5}$. Initial insights into the structural basis for this functional selectivity are beginning to emerge $\mathrm{e}^{38}$. The present study illustrates a unique paradigm for GPCR functional selectivity; namely, the differential ability of ligands to engage similar but distinct G-protein subtypes $^{13}$. Following the same molecular principle as for the $\mathrm{G}$-protein/ $\beta$-arrestin functional selectivity, distinct conformations of the GPCR stabilized by a variety of ligands may also achieve G-protein subtype functional selectivity. Motivated by the unique reciprocal expression patterns of Gs and Golf in the cortex and striatum and the functional distinction in these brain areas, the current study was designed to look for D1R ligands that are functionally selective at Gs versus Golf.

DHX was developed in the late 1980' ${ }^{39}$ and, based on results obtained with the cAMP assay in monkey and rat striatal tissue $^{40,41}$ and behavioral effects in rats ${ }^{42}$, it was introduced as the first fully efficacious D1R agonist with potential antiparkinsonian effects. However, a clinical trial showed marginal therapeutic efficacy and secondary effects including hypotension and tachycardia $^{43}$. The present study gives a new insight into the potential discrepancies previously observed with this drug and 
a

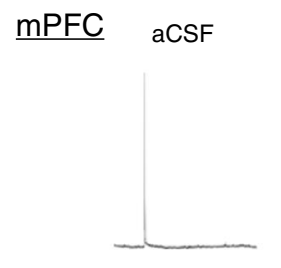

NMDA+SKF

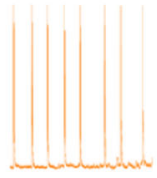

NMDA+DHX

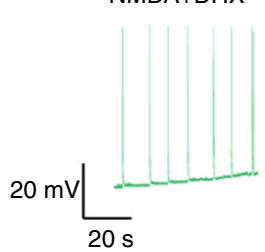

b

$\underline{\mathrm{NAC}}$

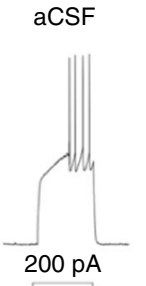

$\mathrm{NMDA}+\mathrm{SKF}$
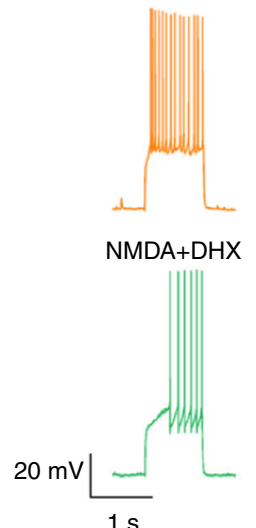

NMDA

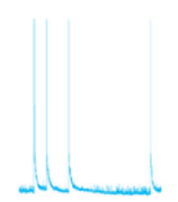

$\mathrm{NMDA}+\mathrm{SKF}+\mathrm{SCH}$

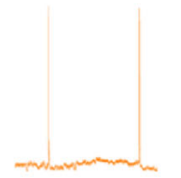

$\mathrm{NMDA}+\mathrm{DHX}+\mathrm{SCH}$

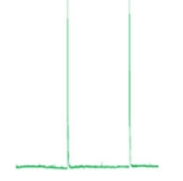

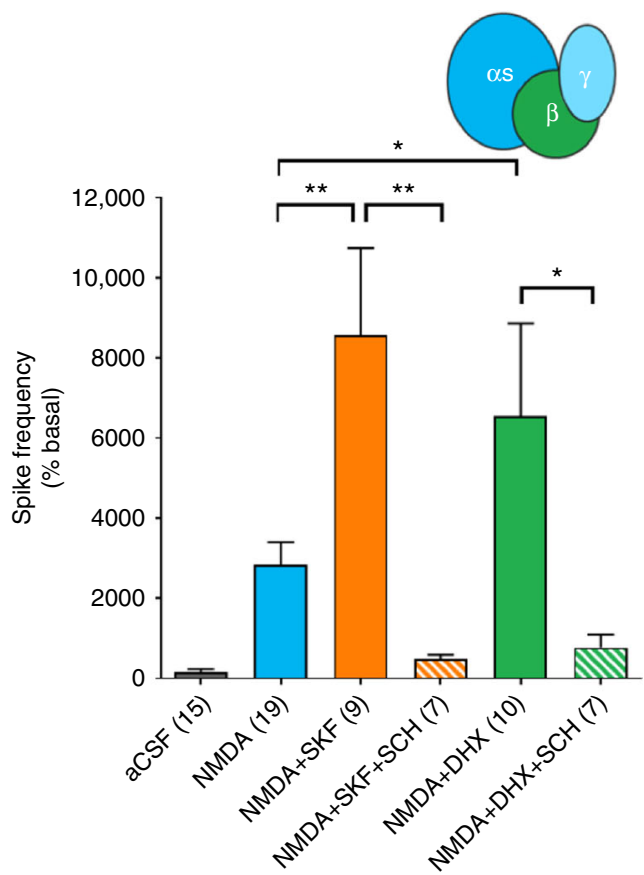

NMDA

$\mathrm{NMDA}+\mathrm{SKF}+\mathrm{SCH}$

$\mathrm{MA}+\mathrm{DHX}+\mathrm{SCH}$
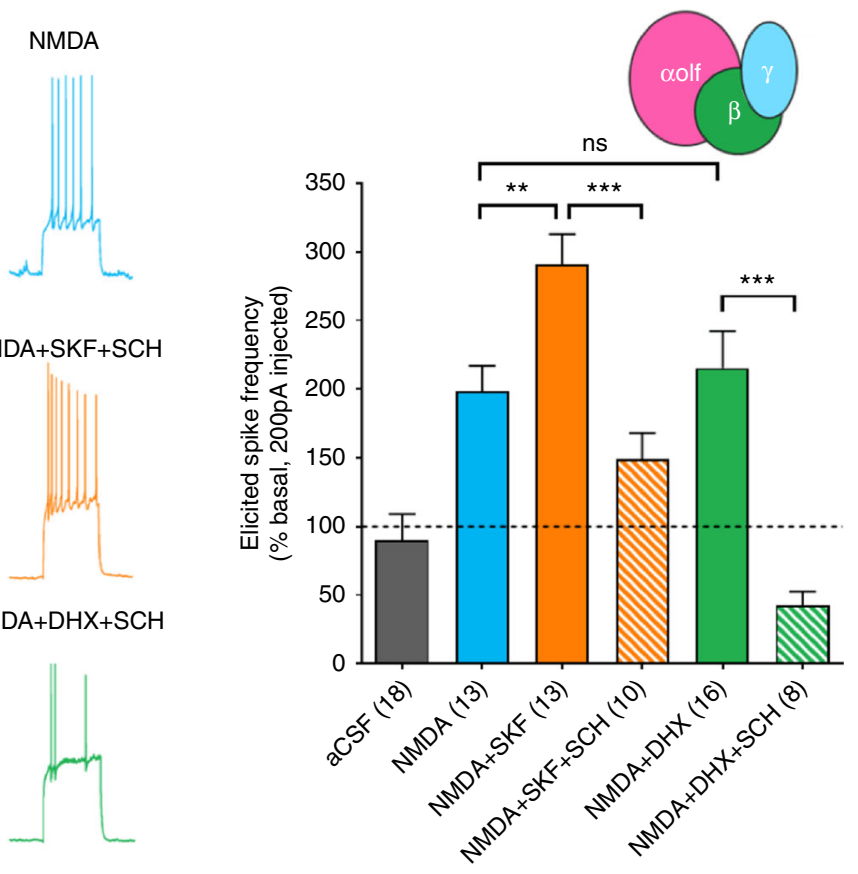

Fig. 4 Current clamp recording of drug-induced firing events for D1R-expressing pyramidal neurons in mPFC (a) and medium spiny neurons in NAc (b). Bar graph shows compiled data for spike frequency over 10 min drug treatment (all $10 \mu \mathrm{M}$ ). For $+\mathrm{SCH} 23390$ condition, the antagonist is added in the aCSF and drug shown in the $x$-axis to ensure antagonist binding prior to the other drug's effect. Example traces are shown on the left. Elicited spike frequency (200 pA injection via recording pipet) is shown for the NAc $\mathbf{b}$. Number of cells recorded for each condition is shown in parenthesis. Values were statistically analyzed by one-way analysis of variance (ANOVA) repeated measure followed by Newman-Keuls post hoc test. $p$-values are as indicated: ${ }^{\star} p<0.05$, ${ }^{\star \star} p$ $<0.01$, or ${ }^{\star \star \star} p<0.001$; NS for not significant. The error bars represent S.E.M.

antiparkinsonian activity of DHX. We find that DHX indeed behaves as a full agonist at D1R, but only when coupled to Gs, not to the predominant striatal G-protein subtype Golf. Based on our molecular modeling study, we propose that the G $\alpha / \alpha \mathrm{N}-\mathrm{D} 1 \mathrm{R} / \mathrm{IL} 2$ interface plays a significant role in determining the reported biased agonism, as implicated by previous studies on differential ligand-induced conformations of the IL2 of monoaminergic receptors ${ }^{44,45}$. Our studies with the chimeric receptor suggest that D1R/IL2 may exist in distinct conformations such that DHX diminishes the already weak G $\alpha / \alpha \mathrm{N}-\mathrm{D} 1 \mathrm{R} / \mathrm{IL} 2$ interaction of D1RGolf coupling, compared to DA. Although previous studies have reported a full efficacy profile reported for DHX, several caveats must be considered. First, the DHX efficacy has been reported in heterologous expression systems ${ }^{46,47}$, which rely mostly on Gs- 
a

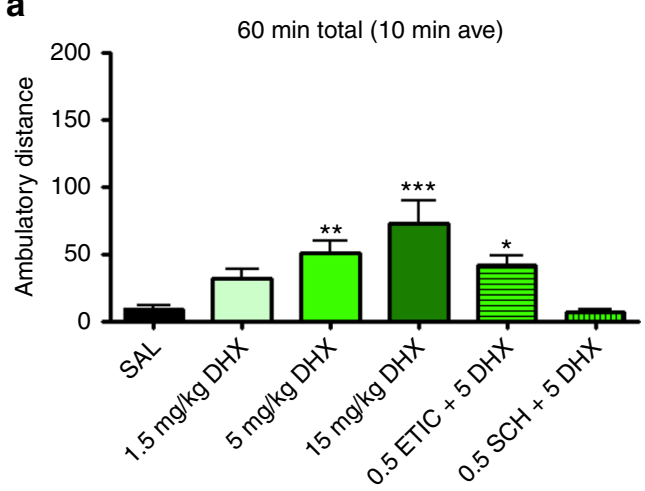

C

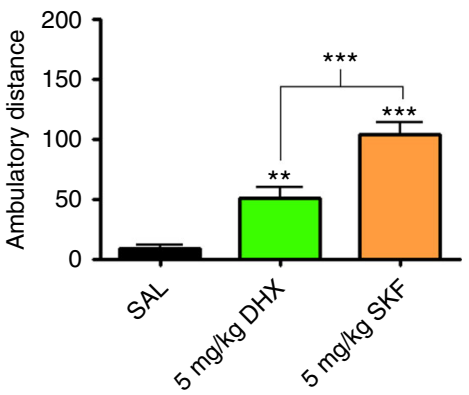

b

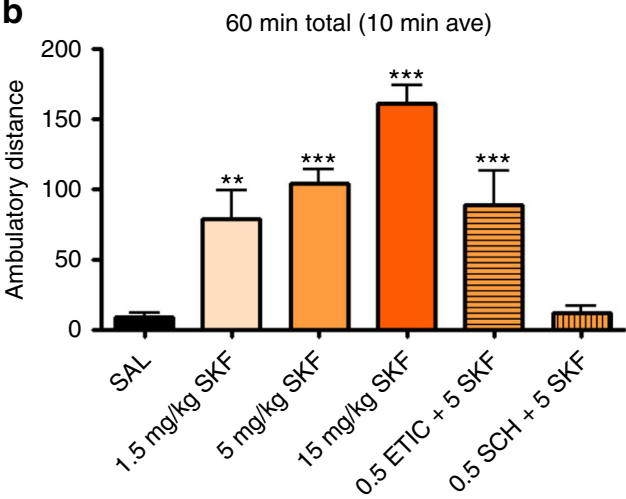

d

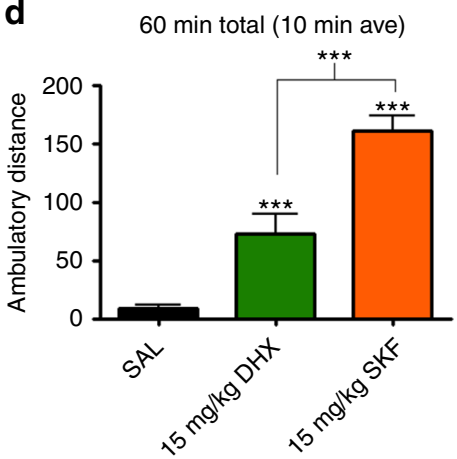

Fig. 5 a, b Effect of D1R agonists on locomotion induced in reserpine-treated mice for DHX (a) and SKF81297 (b). Six bar group represents saline injection, $1.5 \mathrm{mg} / \mathrm{kg}, 5 \mathrm{mg} / \mathrm{kg}, 15 \mathrm{mg} / \mathrm{kg}, 5 \mathrm{mg} / \mathrm{kg}+0.5 \mathrm{mg} / \mathrm{kg}$ eticlopride, $5 \mathrm{mg} / \mathrm{kg}+0.5 \mathrm{mg} / \mathrm{kg} \mathrm{SCH} 23390$ (left to right). c, d Comparison of the ambulatory distance between DHX and SKF81298 at $5 \mathrm{mg} / \mathrm{kg}$ (c) and $15 \mathrm{mg} / \mathrm{kg}$ (d). Values were statistically analyzed by one-way analysis of variance (ANOVA) followed by Newman-Keuls post hoc test. $p$-values are as indicated: ${ }^{\star} p<0.05,{ }^{\star \star} p<0.01$ or ${ }^{\star \star \star} p<0.001$. The error bars represent S.E.M

mediated readout due to the fact that these cells do not express Golf. Second, the apparent full efficacy of DHX observed in experiments from Golf-rich striatal material ${ }^{40,41}$ could be related to the confounding effect of a concomitant Gs-dependent response from D1-like receptors localized in striatal neuronal populations other than medium spiny neurons, such as the large aspiny cholinergic interneurons. Indeed these interneurons are known to contain functional D1-like receptors of D5R subtype ${ }^{48,49}$. Finally, previous in vivo recordings from non-identified ventral pallidal neurons ${ }^{50,51}$ compared the effects of DHX with other $\mathrm{D}_{1}$-like receptor agonists. Single cell recording of $\mathrm{D}_{1}$-like receptor-expressing neurons in the striatum and cortex permitted us to better isolate the Golf- and Gs-dependent effects of D1-like receptor ligands. We could in fact confirm the significant respective predominance of Golf and Gs mRNA expression in these brain areas. We were then able to recapitulate by intracellular recordings the same differential pharmacological properties of DHX observed in vitro, namely striatal Golf-dependent efficacy differences between DHX and the full D1R agonist SKF81297.

Locomotor activation in reserpinized mice has been widely used to characterize striatal post-synaptic DA receptor pharmacology. With short-term reserpinization (about $4 \mathrm{~h}$ ), D1R or D2R agonists produce no or little significant locomotor activation when administered alone, although a strong synergistic effect is observed upon co-administration of D1R and D2R agonists ${ }^{36,37}$. This situation parallels that in non-reserpinized mice, where endogenous dopamine synergizes with the effect of either D1R or D2R agonists. This explains the ability of either D1R or D2R antagonists to counteract the behavioral effects of both D1R or $\mathrm{D} 2 \mathrm{R}$ agonists in non-reserpinized and short-term reserpinized mice ${ }^{36,37}$, as reported for $\mathrm{DHX}^{42}$. In contrast, with long-term reserpinization, synergistic effects of $\mathrm{D}_{1^{-}}$and $\mathrm{D}_{2}$-like receptor agonists wane and administration of either agonist produces significant locomotion, which allows a more accurate pharmacological characterization of dopamine receptor ligands ${ }^{36,37}$. Long-term reserpinized mice were therefore used to establish the selective $\mathrm{D}_{1}$-like receptor partial agonistic profile of DHX. DHX produced a mild locomotor activation that was counteracted by the $\mathrm{D}_{1}$-like receptor antagonist $\mathrm{SCH} 23390$, but not by the $\mathrm{D}_{2}$-like receptor antagonist eticlopride, at the same dose that completely counteracted locomotor activation induced by the D2R agonist quinpirole. This is in spite of previous studies suggesting less potent but efficacious $\mathrm{D}_{2}$-like receptor agonistic properties of $\mathrm{DHX}^{22,52}$. A low potency toward $\mathrm{D}_{2}$-like receptors was also observed in the present study using BRET assays of D1R-, D2R-, and D3R-mediated G-protein activation and AC inhibition. In addition, in the G-protein activation BRET assays, DHX behaved as a partial D2R and D3R agonist as compared with the full agonist quinpirole ( $61.0 \%$ and $55.5 \%$ of quinpirole respectively), which may not be sufficient to trigger $\mathrm{D}_{2}$-like receptor-dependent locomotor activation in the reserpinized animal. The partial agonism of DHX in the reserpinized mice model thus confirms the key role of striatal post-synaptic Golf-dependent D1R in the mediation of locomotor activation induced by D1R agonists. In agreement with the electrophysiological experiments, we were able to recapitulate in vivo the lower efficacy of DHX, as compared to SKF81297, in an assay that depends on striatal D1R activation. Although differences in bioavailability between these two compounds cannot be ruled out, the lack of full efficacy with DHX is likely not due to poor brain availability, based on prior 
pharmacokinetic studies in rats $^{52}$ as well as nonhuman primates ${ }^{53}$. In addition, various functional studies also exhibit a rapid onset of DHX activity in rodent brain ${ }^{50,51,54}$.

In summary, the current study provides the first example of a D1R agonist, DHX, that acts as a full agonist with Gs- and a partial agonist with Golf-dependent signaling. Consequently, DHX behaves as a low efficacy striatal D1R agonist but as a full $\mathrm{D} 1 \mathrm{R}$ agonist in the cortex. This therefore provides a rationale for the use of DHX, or related compounds, in neuropsychiatric disorders with cognitive deficits, which could benefit from selective targeting of cortical D1R. Specifically, pharmacological enhancement D1R activity is being considered as a highly promising therapeutic mechanism for the amelioration of schizophreniaspectrum cognitive deficits. Indeed, recent findings suggest that DHX can be potentially effective for the treatment of schizophrenia-spectrum working memory impairments ${ }^{55}$. The pharmacological characterization presented here, in combination with structure-activity relationship analysis, may lead to the development of compounds that can differentially affect D1R function in different brain regions.

\section{Methods}

DNA constructs. Human receptor constructs (D1R, D2SR, D3R, and muscarinic M1 receptor $[\mathrm{M} 1 \mathrm{R}]$ ) were modified $\mathrm{N}$-terminally with in frame fusion of a signal peptide followed by a Flag or Myc epitope tag for enhanced cell surface expression $^{56}$. D1R fused to Renilla Luciferase 8 (Rluc; provided by Dr. S. Gambhir, Stanford University, Stanford, CA) was described elsewhere ${ }^{57}$. The following nonfusion and fusion human G-protein constructs were used for cAMP accumulation assay and various bioluminescence resonance energy transfer (BRET) assays: Gos short (Goss), Goolf, Goss67-Venus, Goss99-Venus, Gass154-Venus, Goolf69-

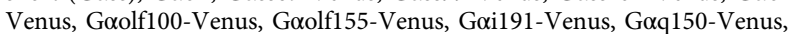

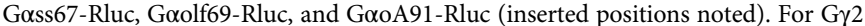
and G $\gamma 7$ GFP10-fusion constructs, full-length GFP10 was fused at its N-terminus. Untagged $\beta \gamma$ subunits G $\beta 2$ and G $\gamma 7$ were also used for co-transfection. G-protein chaperone Ric $8 \mathrm{~B}^{58,59}$ (kind gift from Dr. Gregory Tall) was co-transfected with Goss and Goolf constructs. The cAMP sensor with YFP-Epac-Rluc (CAMYEL) was obtained from ATCC (no. MBA-277) ${ }^{60}$. G-protein receptor kinase 2 (GRK2) and mVenus-fused $\beta$-arrestin- $2^{61}$ constructs were used for $\beta$-arrestin recruitment assay. Adenylate cyclase 5 (AC5, kind gift from Dr. Carmen Dessauer) was modified to generate AC5-NanoLuc (Promega) fusion construct. Both non-fusion and fusion AC5 constructs were used for the cAMP accumulation and BRET assays. All the constructs were confirmed by sequencing analysis.

BRET assays. Variations of bioluminescence resonance energy transfer (BRET) assay were performed to detect receptor ligand-induced events. A constant amount of plasmid cDNA ( $15 \mu \mathrm{g}$ ) was transfected into human embryonic kidney cells $293 \mathrm{~T}$ (HEK-293T) using polyethylenimine (PEI; Sigma) in a 1:2 weight ratio in $10 \mathrm{~cm}$ plates. Cells were maintained in culture with Dulbecco's modified Eagle's medium (DMEM) supplemented with 10\% fetal bovine serum (FBS, Atlanta), $2 \mathrm{mM} \mathrm{L}$ glutamine (Gibco), and $1 \%$ penicillin streptomycin (Gibco) and kept in an incubator at $37^{\circ} \mathrm{C}$ and $5 \% \mathrm{CO}_{2}$. The transfected amount and ratio among the receptor and heterotrimeric $\mathrm{G}$ proteins were tested for optimized dynamic range in drug-induced BRET. Experiments were performed approximately $48 \mathrm{~h}$ posttransfection. As reported previously ${ }^{57}$, cells were collected, washed, and resuspended in phosphate-buffered saline (PBS). Approximately 200,000 cells/well were distributed in 96-well plates, and $5 \mu \mathrm{M}$ coelenterazine $\mathrm{H}$ (luciferase substrate, BRET1) or $5 \mu \mathrm{M}$ coelenterazine $400 \mathrm{a}$ (luciferase substrate, BRET2) was added to each well. One minute after addition of coelenterazine, agonists were added to each well. Antagonists were added $15 \mathrm{~min}$ before the addition of agonist. Five different configurations of BRET were used: (i) Receptor-G $\alpha$ engagement, (ii) $\mathrm{G} \alpha-\gamma$ protein activation, (iii) cAMP production, (iv) $\beta$-arrestin-2 recruitment, and (v) G $\alpha$-AC5 interaction. (i) Receptor-G $\alpha$ engagement assay uses D1R-Rluc-Gos-Venus or D1RRluc-Goolf-Venus for a resonance energy transfer (RET) pair to study co-expressed D1R activity. (ii) $\mathrm{G} \alpha-\gamma$ protein activation assay uses Goss-Rluc- $\gamma 7-\mathrm{GFP} 10$, GoolfRluc- $\gamma 7$-GFP10, or Goo-Rluc- $\gamma 2$-GFP10 for a RET pair. Receptors and untagged G $\beta 2$ constructs were co-transfected; (iii) cAMP production assay uses CAMYEL biosensor construct that contains Rluc and YFP allowing detection of intracellular cAMP change $e^{60}$ in conjunction with receptor co-expression. D1R-Gs activation was studied by agonist-induced cAMP increases. In order to study D2R-or D3RGi/o dependent cAMP inhibition activity, cells were pre-stimulated with $10 \mu \mathrm{M}$ forskolin (Sigma) ten minutes prior to agonist treatment. (iv) $\beta$-arrestin-2 recruitment uses D1R-Rluc- $\beta$-arrestin-2-Venus for a RET pair. GRK2 was cotransfected to assist an enhanced phosphorylation required for the $\beta$-arrestin-2 recruitment. (v) G $\alpha$-AC5 interaction assay uses AC5-Nluc-Goss-Venus or AC5Nluc-Goolf-Venus as a RET pair to study D1R-induced events. The acceptor fluorescence was quantified. Venus was excited at $500 \mathrm{~nm}$ and measured at an emission wavelength of $530 \mathrm{~nm}$. To confirm constant expression levels across experiments, GFP10 was excited at $405 \mathrm{~nm}$ measured at an wavelength emission of $515 \mathrm{~nm}$. Both fluorophores were measured over $1 \mathrm{sec}$ of recording, using a Mithras LB940 microplate reader (Berthold Technologies, Bad Wildbad, Germany).

BRET1 signal from the same batch of cells was calculated as the ratio of the light emitted by Venus $(530 \mathrm{~nm})$ over that emitted by coelenterazine $\mathrm{H}(485 \mathrm{~nm})$, and BRET2 signal from the same batch of cells was calculated as the ratio of the light emitted by GFP10 $(515 \mathrm{~nm})$ over that emitted by coelenterazine $400 \mathrm{a}(400 \mathrm{~nm})$. BRET change was defined as BRET ratio for the corresponding drug minus BRET ratio in the absence of the drug. $E_{\max }$ values are expressed as the basal subtracted BRET change and in the dose-response graphs. Data and statistical analysis were performed with Prism 5 (GraphPad Software).

cAMP accumulation assay in S49 cyc- cells. Mouse lymphoma S49 cyc- Tag cell line, a subclone of cyc- cells that stably expresses simian virus 40 (SV40) large T antigen (TAg), is used for electroporation and subsequent cAMP accumulation assay which is modified from previous study ${ }^{20}$. Cells are maintained in DMEM (Gibco) containing I0\% FBS (Atlanta), 2 mM L-glutamine (Gibco), 1\% penicillin streptomycin (Gibco) as well as $0.6 \mathrm{mg} / \mathrm{ml}$ of geneticin (GIBCO-BRL) to maintain expression of TAg and kept in an incubator at $37^{\circ} \mathrm{C}$ and $5 \% \mathrm{CO}_{2}$. Plasmids carrying D1R, G $\alpha$ ss or Goolf, $\beta 2, \gamma 7$, Ric8B, and AC5 (45 $\mu \mathrm{g}$ total) are electroporated into the cells ( 10 million) by gene pulsar. cAMP assay is performed on cells $48 \mathrm{~h}$ post electroporation. Cells are resuspended in PBS subject to drug treatment20 min agonist or the same with preceded 15 min antagonist incubation at room temperature. The incubation is stopped by centrifugation at $4 \mathrm{C}$, drug removal by aspiration, and cell lysis by $0.1 \mathrm{M} \mathrm{HCl}$. Cell lysate samples are processed to measure cAMP levels by an enzyme-linked immunosorbent assay kit (Enzo Life Sciences, Farmingdale, NY) following manufacturer's protocol. Protein concentration of the cells is determined by the quantitation assay (Pierce BCA protein assay, Thermo).

Homology modeling and molecular dynamics simulation. Phylogenetically D1R is closer to the $\beta 2$ adrenergic receptor $(\beta 2 \mathrm{AR})$ than to any other member of the dopamine receptor subfamily ${ }^{62}$. Thus the models for human D1R-Gs and D1RGolf complexes in active conformation were modeled based on the crystal structure of $\beta 2$ AR-Gs complex (PDB: 3SN6) bound to a full agonist BI-167107. The template $(\beta 2 \mathrm{AR})$-target (D1R) sequence alignment was extracted from G-protein-coupled receptor database (GPCRdb) ${ }^{63}$. The regions that do not have a template in the 32AR structure were not modeled. Five homology models for each of D1R-Gs and D1R-Golf complex were generated using MODELLER (version 9.17) ${ }^{64}$ and the models with the smallest objective function value were selected. To refine and validate the IL2 region of D1R, which is critical in the interaction with the Gs and Golf proteins (see text), we generated an ensemble of IL2 (residues 129-139 in D1R homology model) conformations (800 models) using the Random Coordinate Descent (RCD) algorithm implemented in RCD + webserver ${ }^{65}$. We compared the representative IL2 conformation from the lowest energy cluster of the ensemble with that of the selected homology models, and found they are similar. To further refine the models of the complexes, we used the side-chain prediction function ${ }^{66}$ of Prime program implemented in Schrödinger suite (release 2016-4, Schrödinger, LLC: New York, NY) to optimize the side-chain rotamers of the IL2 (residues 129-139) of the D1R and interacting residues on Gs and Golf (residues 28-40 and 30-42, respectively).

The optimized models were further investigated by molecular dynamics simulations. The simulation systems were built by embedding the D1R/G-protein complexes in the 1-palmitoyl- 2-oleoylphosphatidylcholine lipid bilayer solvent environment using Desmond (version 4.9; D. E. Shaw Research, New York, NY) with OPLS3 force field and TIP3P water model. The charge on the systems was neutralized by adding counter ions and $150 \mathrm{mM} \mathrm{NaCl}$ was added into the systems to attain physiological ionic strength. The system size is 519752 and 513427 atoms for D1R-Gs complex and D1R-Golf complex, respectively. Each system was first minimized and then equilibrated with restraints on the protein backbone-atoms, followed by an isothermal-isobaric simulation at $310 \mathrm{~K}$ with all atoms unrestrained, as described previously ${ }^{67,68}$. In the end, we collected 50 ns simulation time for each system.

Animals. Male D1-tdtomato reporter BAC mice in C57BL/6 J background (Drd1tdTomato line 6, Jackson Lab) were used for single cell reverse transcription PCR (RT-PCR) and slice electrophysiology experiments. Male wildtype C57BL/6 J mice were used for locomotor activity experiments. Animals were housed with food and water available ad libitum in temperature-controlled and humidity-controlled rooms and were maintained on a $12 \mathrm{~h}$ light/dark cycle. They were experimentally naive at the start of the study and were maintained under the approved protocol of the Institutional Care and Use Committee of the Intramural Research Program, National Institute on Drug Abuse. 
Single cell or tissue extraction RT-PCR. Quantitative real-time RT-PCR was performed and analyzed using LightCycler instrument 480 II (Roche). Coronal slices were prepared as described in slice electrophysiology. For D1R-expressing single cell analysis, Drd1-tdTomato mice were used. After identifying Drd1tdTomato positive cells, cytoplasmic content was collected by micro pipet aspiration for single cell analyses. For tissue extracted analysis, wild type tissue samples were obtained in corresponding brain and processed for cell plasm. Collected cell plasm was immersed in buffer provided in a PicoPure RNA isolation kit (Invitrogen Life Technologies/Arcturus), and total RNA was isolated according to kit directions. Total RNA was converted to cDNA, then cDNA was amplified to antisense RNA (aRNA) by in vitro transcribe using the Message BOOSTER cDNA Synthesis Kit for qPCR (Epicentre Technologies, Madison, WI). The aRNA was purified using Qiagen RNeasy MinElute Cleanup kit and transcript to cDNA using SuperScript III Reverse Transcriptase (Invitrogen). PCR reactions were done in a total volume of $20 \mu \mathrm{L}$ in PCR mix containing $10 \mu \mathrm{L} 2 \mathrm{X}$ LightCycler probe master, $500 \mathrm{nM}$ reference gene primer (GAPDH), $500 \mathrm{nM}$ each of sense and antisense primer, $100 \mathrm{nM}$ each of target gene probe and reference gene probe, and $5 \mu \mathrm{L}$ of 100ng cDNA filled up to $20 \mu \mathrm{L}$ with DEPC-treated $\mathrm{H}_{2} \mathrm{O}$. Normalization of sample cDNA content was performed using the comparative threshold $(\Delta \Delta \mathrm{CT})$ cycle method, in which the number of target gene copies was normalized to an endogenous reference gene, GAPDH. CT is defined as the fractional cycle number at which the fluorescence generated by probe cleavage passes a fixed threshold baseline when amplification of the PCR product is first detected. The primers and probes were designed using Universal Probe Library Assay Design Center (Roche). Primer sequences and probes are as follows: $5^{\prime}$-gcagaaggacaagcaggtct- $3^{\prime}$ (G $\alpha$ s forward), 5'-gcttttgccagactctccag- $3^{\prime}$ (Gos reverse), 5'-atccgggatctgttcttgag- $3^{\prime}$ (Goolf forward), 5'-caggtgaagtgagggtagcag- $3^{\prime}$ (Goolf reverse), 5'-atggtgaaggtcggtgtga- $3^{\prime}$ (GADPH forward), and 5'-aatctccactttgccactgc-3' (GADPH reverse).

Slice electrophysiology. Experiments were performed based on previous report with modifications ${ }^{69}$. Coronal slices $(220 \mu \mathrm{m})$ were prepared from male adult Drd1-tdTomato mice using a vibrating tissue slicer (VT-1000S, Leica). Animals were anesthetized and perfused with modified artificial cerebral spinal fluid (maCSF) containing (in mM): 92 NMDG, 20 HEPES, 25 glucose, $30 \mathrm{NaHCO}_{3}, 1.2$ $\mathrm{NaH}_{2} \mathrm{PO}_{4}, 2.5 \mathrm{KCl}, 5$ sodium ascorbate, 3 sodium pyruvate, 2 thiourea, $10 \mathrm{MgSO}_{4}$, $0.5 \mathrm{CaCl}_{2}, 300-310 \mathrm{mOsm}$, and $\mathrm{pH}$ 7.3-7.4. Slices were sectioned in cold $\mathrm{m}$-aCSF and recovered at $32{ }^{\circ} \mathrm{C}$ in the same buffer saturated with $95 \% \mathrm{O}_{2}$ and $5 \% \mathrm{CO}_{2}$ (carbogen) for $10 \mathrm{~min}$. Slices were then transferred to a holding chamber filled with carbogen saturated aCSF (holding aCSF) containing, in mM: $92 \mathrm{NaCl}, 20 \mathrm{HEPES}$, 25 glucose, $30 \mathrm{NaHCO}_{3}, 1.2 \mathrm{NaH}_{2} \mathrm{PO}_{4}, 2.5 \mathrm{KCl}, 5$ sodium ascorbate, 3 sodium pyruvate, 2 thiourea, $1 \mathrm{MgSO}_{4}, 2 \mathrm{CaCl}_{2}, 300-310 \mathrm{mOsm}$, and $\mathrm{pH}$ 7.3-7.4. During recordings, slices were continuously perfused at $2 \mathrm{ml} / \mathrm{min}$ with carbogen-saturated aCSF containing (in mM): $124 \mathrm{NaCl}, 2.5 \mathrm{KCl}, 1.25 \mathrm{NaH}_{2} \mathrm{PO}_{4}, 1 \mathrm{MgCl}_{2}, 26$ $\mathrm{NaHCO}_{3}, 11$ glucose, $2.4 \mathrm{CaCl}_{2}, 300-310$ mOsm, and $\mathrm{pH} 7.3-7.4$, supplemented with $200 \mu \mathrm{M}$ sodium bisulfite, $100 \mu \mathrm{M}$ picrotoxin and $10 \mu \mathrm{M}$ eticlopride. The temperature of the recording chamber was maintained at $31-32^{\circ} \mathrm{C}$. Electrodes $(3-5$ $\mathrm{M} \Omega$ ) were backfilled with an internal solution containing (in $\mathrm{mM}$ ): $120 \mathrm{mM} \mathrm{K}$ gluconate, $20 \mathrm{KCl}, 0.05$ EGTA, 10 HEPES, 1.5 $\mathrm{MgCl}_{2}, 2.18 \mathrm{Na}_{2}$ ATP, $0.38 \mathrm{Na}$ GTP, $10.19 \mathrm{Na}$ phosphocreatine, $280-285 \mathrm{mOsm}$, and $\mathrm{pH}$ 7.3-7.4. Cells were visualized on an upright microscope using infrared differential interference contrast video microscopy. Whole-cell current-clamp recordings were made using a MultiClamp $700 \mathrm{~B}$ amplifier ( $2 \mathrm{kHz}$ low-pass Bessel filter and $10 \mathrm{kHz}$ digitization) with pClamp 10.5 software (Molecular Devices). Pyramidal neurons in the layer V prelimbic cortex and medium spiny neurons in the medial NAc shell were identified by morphology, membrane resistance, and hyperpolarized resting membrane potential. Series resistance (10-25 M 2 ) was monitored with a $5 \mathrm{mV}$ hyperpolarizing pulse $(50 \mathrm{~ms})$ given every $20 \mathrm{~s}$, and only recordings that remained stable (monitored by series resistance) over the period of data collection were used. On breaking into neurons, the resting membrane potentials were between -70 and -90 $\mathrm{mV}$. Current pulses (200 pA) were applied to medium spiny neurons using Clampex 10.5 and a MultiClamp 700B amplifier in current-clamp mode (Molecular Devices). All data are reported as mean \pm SEM. Data was analyzed in Clampex and statistically analyzed with Prism 5 (GraphPad Software) by one-way ANOVA followed by Newman-Keuls post hoc test.

Locomotor behavior assay. Experiments were based on a previous study ${ }^{70}$. Activity chambers with $42.0 \times 42.0 \mathrm{~cm}$ open fields (Coulbourn Instruments, Allentown, PA) were used for the experiments with wild type C57BL/6 J mice. Reserpine (Sigma) was dissolved in a drop of glacial acetic acid, which was brought to volume with $5.5 \%$ glucose, then administered $(5 \mathrm{mg} / \mathrm{kg})$ subcutaneously $20 \mathrm{~h}$ prior to the start of the locomotor activity recording. All the other drugs (SKF81297, DHX, quinpirole, SCH23390, and eticlopride) were dissolved in sterile saline and administered intraperitoneally. Antagonists (SCH23390 or eticlopride) were administered $15 \mathrm{~min}$ prior to the locomotor activity recording and agonists (SKF81297, DHX, or quinpirole) were administered immediately before the animals were introduced in the open field for recording (at least $n=8$ per each drug condition). All values (in $\mathrm{cm}$ of ambulation) registered per $10 \mathrm{~min}$ period were averaged for the first hour of recording. Different drug treated conditions were analyzed by one-way ANOVA followed by post hoc Tukey test.
Data availability. All data that support the findings of this study are available from the corresponding author upon request.

Received: 10 June 2017 Accepted: 9 December 2017

Published online: 05 February 2018

\section{References}

1. Kenakin, T. New concepts in pharmacological efficacy at 7TM receptors: IUPHAR review 2. Br. J. Pharmacol. 168, 554-575 (2013).

2. Urban, J. D. et al. Functional selectivity and classical concepts of quantitative pharmacology. J. Pharmacol. Exp. Ther. 320, 1-13 (2007).

3. van der Westhuizen, E. T., Valant, C., Sexton, P. M. \& Christopoulos, A. Endogenous allosteric modulators of $\mathrm{G}$ protein-coupled receptors. $J$. Pharmacol. Exp. Ther. 353, 246-260 (2015).

4. Ritter, S. L. \& Hall, R. A. Fine-tuning of GPCR activity by receptor-interacting proteins. Nat. Rev. Mol. Cell. Biol. 10, 819-830 (2009).

5. Violin, J. D., Crombie, A. L., Soergel, D. G. \& Lark, M. W. Biased ligands at G-protein-coupled receptors: promise and progress. Trends Pharmacol. Sci. 35, 308-316 (2014).

6. Free, R. B. et al. Discovery and Characterization of a G Protein-Biased Agonist That Inhibits $\beta$-Arrestin Recruitment to the D2 Dopamine Receptor. Mol. Pharmacol. 86, 96-105 (2014).

7. Szabo, M., Klein Herenbrink, C., Christopoulos, A., Lane, J. R. \& Capuano, B. Structure-Activity Relationships of Privileged Structures Lead to the Discovery of Novel Biased Ligands at the Dopamine D2 Receptor. J. Med. Chem. 57, 4924-4939 (2014).

8. Allen, J. A. et al. Discovery of $\beta$-arrestin-biased dopamine D2 ligands for probing signal transduction pathways essential for antipsychotic efficacy. Proc. Natl Acad. Sci. USA 108, 18488-18493 (2011).

9. Weichert, D. et al. Molecular determinants of biased agonism at the dopamine D2 receptor. J. Med. Chem. 58, 2703-2717 (2015).

10. Ryman-Rasmussen, J. P. et al. Functional selectivity of dopamine D1 receptor agonists in regulating the fate of internalized receptors. Neuropharmacology $\mathbf{5 2}$ 562-575 (2007).

11. Ryman-Rasmussen, J. P., Nichols, D. E. \& Mailman, R. B. Differential Activation of adenylate cyclase and receptor internalization by novel dopamine D1 receptor agonists. Mol. Pharmacol. 68, 1039-1048 (2005).

12. Conroy, J. L., Free, R. B. \& Sibley, D. R. Identification of G protein-biased agonists that fail to recruit $\beta$-arrestin or promote internalization of the D1 dopamine receptor. ACS Chem. Neurosci. 6, 681-692 (2015).

13. Sánchez-Soto, M. et al. Evidence for noncanonical neurotransmitter activation: norepinephrine as a dopamine D2-like receptor agonist. Mol. Pharmacol. 89, 457-466 (2016).

14. Zhuang, X., Belluscio, L. \& Hen, R. GOLF alpha mediates dopamine D1 receptor signaling. J. Neurosci. 20, RC91 (2000).

15. Herve, D. et al. G(olf) and Gs in rat basal ganglia: possible involvement of G (olf) in the coupling of dopamine D1 receptor with adenylyl cyclase. J. Neurosci. 13, 2237-2248 (1993).

16. Hervé, D. Identification of a specific assembly of the $G$ protein golf as a critical and regulated module of dopamine and adenosine-activated cAMP pathways in the striatum. Front. Neuroanat. 5, 48 (2011).

17. Arnsten, A. F. T., Girgis, R. R., Gray, D. I. \& Mailman, R. B. Novel dopamine therapeutics for cognitive deficits in schizophrenia. Biol. Psychiatry 81, 67-77 (2017).

18. Shenoy, S. K. \& Lefkowitz, R. J. $\beta$-arrestin-mediated receptor trafficking and signal transduction. Trends Pharmacol. Sci. 32, 521-533 (2011).

19. Urs, N. M., Daigle, T. L. \& Caron, M. G. A dopamine D1 receptor-dependent $\beta$ arrestin signaling complex potentially regulates morphine-induced psychomotor activation but not reward in mice. Neuropsychopharmacology 36, 551-558 (2011).

20. Berlot C. H. Expression and functional analysis of $\mathrm{G}$ protein $\alpha$ subunits in S49 lymphoma cells. Methods Enzymol. 344, 261-277 (2002).

21. Zhang, J., Xiong, B., Zhen, X. \& Zhang, A. Dopamine D1 receptor ligands: where are we now and where are we going. Med. Res. Rev. 29, 272-294 (2009).

22. Mottola, D. M., Brewster, W. K., Cook, L. L., Nichols, D. E. \& Mailman, R. B. Dihydrexidine, a novel full efficacy D1 dopamine receptor agonist. J. Pharmacol. Exp. Ther. 262, 383-393 (1992).

23. Fiorentini, C. et al. Reciprocal regulation of dopamine D1 and D3 receptor function and trafficking by heterodimerization. Mol. Pharmacol. 74, 59-69 (2008).

24. Huppé-Gourgues, F. \& O’Donnell, P. D1-NMDA receptor interactions in the rat nucleus accumbens change during adolescence. Synapse 66, 584-591 (2012). 
25. Cepeda, C. et al. Differential electrophysiological properties of dopamine D1 and D2 receptor-containing striatal medium-sized spiny neurons. Eur. J. Neurosci. 27, 671-682 (2008).

26. Flores-Hernández, J., et al. Dopamine enhancement of NMDA currents in dissociated medium-sized striatal neurons: role of D1 receptors and DARPP32. J. Neurophysiol. 88, 3010-3020 (2002).

27. Wang, J. \& O'Donnell, P. D1 dopamine receptors potentiate NMDA-mediated excitability increase in layer V prefrontal cortical pyramidal neurons. Cereb. Cortex. 11, 452-462 (2001).

28. Tseng, K. Y. \& O'Donnell, P. Dopamine-glutamate interactions controlling prefrontal cortical pyramidal cell excitability involve multiple signaling mechanisms. J. Neurosci. 24, 5131-5139 (2004).

29. Chen, G., Greengard, P. \& Yan, Z. Potentiation of NMDA receptor currents by dopamine D1 receptors in prefrontal cortex. Proc. Natl Acad. Sci. USA 101, 2596-2600 (2004).

30. Cahill, E. et al. D1R/GluN1 complexes in the striatum integrate dopamine and glutamate signalling to control synaptic plasticity and cocaine-induced responses. Mol. Psychiatry 19, 1295-1304 (2014).

31. Ladepeche, L. et al. Single-molecule imaging of the functional crosstalk between surface NMDA and dopamine D1 receptors. Proc. Natl Acad. Sci. USA 110, 18005-18010 (2013)

32. Lee, F. J. S. et al. Dual regulation of NMDA receptor functions by direct protein-protein interactions with the dopamine D1 receptor. Cell 111, 219-230 (2002).

33. Svenningsson, P. et al. DARPP-32: an integrator of neurotransmission. Annu. Rev. Pharmacol. Toxicol. 44, 269-296 (2004).

34. Hernández-López, S., Bargas, J., Surmeier, D. J., Reyes, A. \& Galarraga, E. D1 receptor activation enhances evoked discharge in neostriatal medium spiny neurons by modulating an L-type Ca2+ conductance. J. Neurosci. 17, 3334-3342 (1997).

35. Cui, C., Xu, M. \& Atzori, M. Voltage-dependent block of N-methyl-D-aspartate receptors by dopamine D1 receptor ligands. Mol. Pharmacol. 70, 1761-1770 (2006).

36. Ferré, S., Giménez-Llort, L., Artigas, F. \& Martínez, E. Motor activation in short- and long-term reserpinized mice: role of N-methyl-D-aspartate, dopamine D1 and dopamine D2 receptors. Eur. J. Pharmacol. 255, 203-213 (1994).

37. Starr, B. S., Starr, M. S. \& Kilpatrick, I. C. Behavioural role of dopamine D1 receptors in the reserpine-treated mouse. Neuroscience 22, 179-188 (1987).

38. Wacker, D. et al. Structural features for functional selectivity at serotonin receptors. Science 340, 615-619 (2013).

39. Lovenberg, T. W. et al. Dihydrexidine, a novel selective high potency full dopamine D-1 receptor agonist. Eur. J. Pharmacol. 166, 111-113 (1989).

40. Watts, V. J. et al. Dopamine D1 receptors: efficacy of full (dihydrexidine) vs. partial (SKF38393) agonists in primates vs. rodents. Eur. J. Pharmacol. 242, 165-172 (1993).

41. Izenwasser, S. \& Katz, J. L. Differential efficacies of dopamine D1 receptor agonists for stimulating adenylyl cyclase in squirrel monkey and rat. Eur. J. Pharmacol. 246, 39-44 (1993).

42. Darney, K. J. Jr et al. Behavioral effects in the rat of dihydrexidine, a highpotency, full-Efficacy D1 dopamine receptor agonist. Neuropsychopharmacology 5, 187-195 (1991).

43. Blanchet, P. J. et al. Effects of the full dopamine D1 receptor agonist dihydrexidine in Parkinson's disease. Clin. Neuropharmacol. 21, 339-343 (1998).

44. Perez-Aguilar, J. M., Shan, J., LeVine, M. V., Khelashvili, G. \& Weinstein, H. A functional selectivity mechanism at the serotonin-2A GPCR involves liganddependent conformations of intracellular loop 2. J. Am. Chem. Soc. 136, 16044-16054 (2014).

45. Venkatakrishnan, A. J. et al. Molecular signatures of G-protein-coupled receptors. Nature 494, 185-194 (2013).

46. Cueva, J. P. et al. Trans-2,3-dihydroxy-6a,7,8,12b-tetrahydro-6H-chromeno $[3,4-c]$ isoquinoline: synthesis, resolution, and preliminary pharmacological characterization of a new dopamine D1 receptor full agonist. J. Med. Chem. 49, 6848-6857 (2006).

47. Przybyla, J. A. et al. Comparison of the enantiomers of ( \pm )-doxanthrine, a high efficacy full dopamine D1 receptor agonist, and a reversal of enantioselectivity at D1 versus alpha2C adrenergic receptors. Eur. Neuropsychopharmacol. 19, 138-146 (2009).

48. Bergson, C. et al. Regional, cellular, and subcellular variations in the distribution of D1 and D5 dopamine receptors in primate brain. J. Neurosci. 15, 7821-7836 (1995).

49. Berlanga, M. L., Simpson, T. K. \& Alcantara, A. A. Dopamine D5 receptor localization on cholinergic neurons of the rat forebrain and diencephalon: A potential neuroanatomical substrate involved in mediating dopaminergic influences on acetylcholine release. J. Comp. Neurol. 492, 34-49 (2005).
50. Ruskin, D. N., Rawji, S. S. \& Walters, J. R. Effects of full D1 dopamine receptor agonists on firing rates in the globus pallidus and substantia nigra pars compacta in vivo: tests for D1 receptor selectivity and comparisons to the partial agonist SKF 38393. J. Pharmacol. Exp. Ther. 286, 272-281 (1998).

51. Heidenreich, B. A., Mailman, R. B., Nichols, D. E. \& Napier, T. C. Partial and full dopamine D1 agonists produce comparable increases in ventral pallidal neuronal activity: contribution of endogenous dopamine. J. Pharmacol. Exp. Ther. 273, 516-525 (1995).

52. Mottola, D. M. et al. Functional selectivity of dopamine receptor agonists. I. Selective activation of postsynaptic dopamine D2 receptors linked to adenylate cyclase. J. Pharmacol. Exp. Ther. 301, 1166-1178 (2002).

53. Slifstein, M. et al. Characterization of in vivo pharmacokinetic properties of the dopamine D1 receptor agonist DAR-0100A in nonhuman primates using PET with [11C] NNC112 and [11C] raclopride. J. Cereb. Blood. Flow. Metab. 31, 293-304 (2011).

54. Steele, T. D., Hodges, D. B. Jr, Levesque, T. R. \& Locke, K. W. D1 agonist dihydrexidine releases acetylcholine and improves cognitive performance in rats. Pharmacol. Biochem. Behav. 58, 477-483 (1997).

55. Rosell, D. R. et al. Effects of the D1 dopamine receptor agonist dihydrexidine (DAR-0100A) on working memory in schizotypal personality disorder. Neuropsychopharmacology 40, 446-453 (2015).

56. Guan, X. M., Tong Sun, K. \& Kobilka, B. K. Enhancement of membrane insertion and function in a type IIIb membrane protein following introduction of a cleavable signal peptide. J. Biol. Chem. 267, 21995-21998 (1992).

57. Urizar, E. et al. CODA-RET reveals functional selectivity as a result of GPCR heteromerization. Nat. Chem. Biol. 7, 624-630 (2011).

58. Tall, G. G., Krumins, A. M. \& Gilman, A. G. Mammalian Ric-8A (Synembryn) is a heterotrimeric $\mathrm{G} \alpha$ protein guanine nucleotide exchange factor. J. Biol. Chem. 278, 8356-8362 (2003).

59. Von Dannecker L. E., Mercadante, A. F. \& Malnic, B. Ric-8B, an olfactory putative GTP Exchange factor, amplifies signal transduction through the olfactory-specific G-protein Goolf. J. Neurosci. 25, 3793-3800 (2005).

60. Jiang, L. I. et al. Use of a cAMP BRET sensor to characterize a novel regulation of cAMP by the sphingosine 1-phosphate/G13 pathway. J. Biol. Chem. 282, 10576-10584 (2007).

61. Vishnivetskiy, S. A. et al. Few residues within an extensive binding interface drive receptor interaction and determine the specificity of arrestin proteins. J. Biol. Chem. 286, 24288-24299 (2011).

62. Fredriksson, R., Lagerström, M. C., Lundin, L.-G. \& Schiöth, H. B. The Gprotein-coupled receptors in the human genome form five main families. phylogenetic analysis, paralogon groups, and fingerprints. Mol. Pharmacol. 63, 1256-1272 (2003).

63. Isberg, V. et al. GPCRdb: an information system for G protein-coupled receptors. Nucleic Acids Res. 44, D356-D364 (2016).

64. Šali, A. \& Blundell, T. L. Comparative protein modelling by satisfaction of spatial restraints. J. Mol. Biol. 234, 779-815 (1993).

65. López-Blanco, J. R., Canosa-Valls, A. J., Li, Y. \& Chacón, P. RCD+ : Fast loop modeling server. Nucleic Acids Res. 44, W395-W400 (2016).

66. Jacobson, M. P. et al. A hierarchical approach to all-atom protein loop prediction. Protein.: Struct., Funct. Genet. 55, 351-367 (2004).

67. Michino, M., Free, R. B., Doyle, T. B., Sibley, D. R. \& Shi, L. Structural basis for $\mathrm{Na}(+)$-sensitivity in dopamine D2 and D3 receptors. Chem. Commun. 51, 8618-8621 (2015).

68. Michino, M. et al. Toward understanding the structural basis of partial agonism at the dopamine D3 receptor. J. Med. Chem. 60, 580-593 (2017).

69. Hopf, F. W., Cascini, M. G., Gordon, A. S., Diamond, I. \& Bonci, A. Cooperative activation of dopamine D1 and D2 receptors increases spike firing of nucleus accumbens neurons via G-protein betagamma subunits. J. Neurosci. 23, 5079-5087 (2003).

70. Marcellino, D. et al. Identification of dopamine D1-D3 receptor heteromers: indications for a role of synergistic D1-D3 receptor interactions in the striatum. J. Biol. Chem. 283, 26016-26025 (2008).

\section{Acknowledgements}

Work was supported by the Intramural funds of the National Institute on Drug Abuse (S.F., A.B., and L.S.), a fellowship from the Japan Society for the Promotion of Science (H.Y.), and by NIMH grant MH054137 (J.A.J.). We would like to thank Dr. John Northup for discussion on the use of $\$ 49$ cells, Dr. Catherine Berlot for S49 cell technical advice, Dr. Gregory Tall for Ric8 constructs, Dr. Carmen Dessauer for AC5 construct, Drs. Hau-Jie Yau and Marco Pignatelli for the help to set up electrophysiological recording, Drs. Nevin Lambert and Céline Gales for G-protein constructs, and Dr. Tsung Ping Su for the use of RT-PCR thermocycler.

\section{Author contributions}

H.Y. designed, conducted, and analyzed the molecular biology, BRET experiments, and slice electrophysiology. M.X., R.K.V., and L.S. conducted and analyzed the molecular dynamics simulation. W.R. performed and analyzed the mouse behavior experiments. 
N.S.C. performed the molecular biology work. H.Y., J.A.J., A.B., and S.F. wrote the manuscript. All authors contributed to reviewing the results and writing the manuscript.

\section{Additional information}

Supplementary Information accompanies this paper at https://doi.org/10.1038/s41467017-02606-w.

Competing interests: The authors declare no competing financial interests.

Reprints and permission information is available online at http://npg.nature.com/ reprintsandpermissions/

Publisher's note: Springer Nature remains neutral with regard to jurisdictional claims in published maps and institutional affiliations. (c) Open Access This article is licensed under a Creative Commons Attribution 4.0 International License, which permits use, sharing, adaptation, distribution and reproduction in any medium or format, as long as you give appropriate credit to the original author(s) and the source, provide a link to the Creative Commons license, and indicate if changes were made. The images or other third party material in this article are included in the article's Creative Commons license, unless indicated otherwise in a credit line to the material. If material is not included in the article's Creative Commons license and your intended use is not permitted by statutory regulation or exceeds the permitted use, you will need to obtain permission directly from the copyright holder. To view a copy of this license, visit http://creativecommons.org/ licenses/by/4.0/.

(C) The Author(s) 2018 